\title{
"NEO X NEO": O PAPEL DA TRANSNACIONALIZAÇ̃O SINDICAL NOS DEBATES TEÓRICOS DAS RELAÇÕES INTERNACIONAIS NA DÉCADA DE 1970
}

\author{
ESPÓSITO, Katiuscia Moreno Galhera ${ }^{1}$
}

\section{Resumo}

O presente trabalho visa compreender e localizar historicamente alguns debates acadêmicos das Relações Internacionais em torno do fenômeno da transnacionalização das relações de trabalho ocorridos a partir da década de 70.

Especificamente, o exame será realizado sobre a transnacionalização sindical, dentro de dois debates específicos: o (neo) realismo e o (neo) liberalismo, tendo como pano de fundo alguns acontecimentos memoráveis, como o descongelamento das relações Leste-Oeste sob a Guerra Fria, a Guerra do Vietnã, o Tratado de Não-Proliferação Nuclear, a Organização dos Países Exportadores de Petróleo, Bretton Woods, os New Industrialized Countries (NICs) e a Comissão Econômica para América Latina e Caribe (CEPAL).

Tendo abordado os dois paradigmas, em um segundo momento, sob os auspícios da literatura neoliberal, abordaremos algumas questões que problematizam e enriquecem este debate: universalidade vs. relatividade; spillover vs. exclusão e soberania vs. intervencionismo. 
Ao final do artigo procuraremos demonstrar a efetiva internacionalização das demandas de trabalhadores, via estudo de caso (BASF), ocorrida justamente no período em questão (década de 70).

O método utilizado será o indutivo. Partiremos da realidade concreta para formular conclusões que acreditamos parcialmente livres de preceitos prescritos.

Palavras-chave: Relações Internacionais. (neo) realismo. (neo) liberalismo. Sindicalismo. Anos 1970.

\section{Abstract}

The article aims to understand and localize some historically academic debates of International Relations around the phenomenon of transnationalization of labor relations which occurred in the 70's.

Specifically, the study is going to be placed on the unions' transnationalization, in two specific debates: the (neo) realism and the (neo) liberalism, with the backdrop of some memorable events as the deténte of East-West relations in the Cold War, the Vietnam War, the Nuclear Non-Proliferation Treaty, the Organization of Petroleum Exporting Countries, Bretton Woods, the New Industrialized Countries (NICs) and the Economic Commission for Latin America and the Caribbean.

Having addressed the two paradigms, at a second stage and under the auspices of neo-liberal literature, we are going to discuss some issues which enrich this debate: universality / relativity; spillover / exclusion and sovereignty / intervention. 
InterAção | 163

At the end of the article, we will try to demonstrate the effective internationalization of the labor demands (BASF case), which occurred at the period (70's).

The method used is inductive. Based on a real case, we will formulate conclusions that we believe free of formulated conclusions.

Key-words: International Relations.(neo) realism. (neo) liberalism. Unionism. The 70's.

\section{INTRODUÇÃO}

A década de 70 apresentou-se como um marco para as Relações Internacionais (RI). Acontecimentos desse período, como deténte, Guerra do Vietnã, Tratado de Não-Proliferação Nuclear (TNP) e a Organização dos Países Exportadores de Petróleo (OPEP), apenas para citarmos alguns, afetaram pessoas, instituições e países e refletem no cotidiano de diversos atores até os dias atuais.

Como de praxe, tendo em vista a dimensão dos fatos e suas consequências, esta década trouxe, para o debate acadêmico, novas e renovadas contribuições de duas conhecidas escolas teóricas: o Realismo (transformado em Realismo Clássico) e o Liberalismo (ou Idealismo). Reformuladas, tais correntes de pensamento se concretizariam no chamado Debate Racionalista, onde Neo-realistas (ou Realistas Estruturais) contrapunham suas idéias aos Neo-liberais, enriquecendo a produção intelectual na área. $\mathrm{O}$ "Primeiro Grande Debate", realizado entre os "realistas modernos" (1939-1979) teve fim justamente nesta década, com a publicação da obra de Kenneth 
164 | InterAção

Waltz, "Theory of International Politics" (1979).

As mudanças foram visíveis: se antes o Realismo, calcado na visão estadocêntrica de processos e atores, se focava em premissas como raison d'état, segurança, sobrevivência, auto-ajuda, anarquia, interesse nacional e balança de poder, dentre outros, durante os anos 1970 tal arcabouço teórico parecia insuficiente para explicar o Sistema Internacional (SI), como veremos em pormenores no próximo item deste artigo. $\mathrm{O}$ próprio conceito de SI certamente sofreu nova reflexão por parte dos realistas clássicos, afinal, como explicar que organizações afetassem países, como foi o caso da OPEP, e não o oposto, como pregava o Realismo Clássico?

O Liberalismo, por sua vez, encontrava-se desacreditado nos meios acadêmicos por sua visão "idealista" de mundo: fé em uma moral universal e em sua conseqüente cooperação guiada pelo individualismo livre e tolerante, SI ordenado, paz democrática, desenvolvimento, harmonia de interesses e autodeterminação dos povos eram temas ultrapassados e comprovadamente inócuos na prática. Contudo, a partir dos 70, o (neo) liberalismo ganha novos contornos, níveis de análise, metodologia, adeptos e premissas. Ressurge uma escola, agora reformulada e correspondente às demandas práticas das RI.

A transnacionalização do movimento sindical ${ }^{2}$ na forma em que a estudamos ${ }^{3}$ ocorre justamente a partir da década em questão e

2 Destacamos que sempre existiu, dentro do sindicalismo, movimento transnacionais, como a $1^{\text {a }}$. Internacional Comunista, por exemplo. Outra demonstração do transnacionalismo sindical é o famigerado Manifesto Comunista: "operários do mundo, uni-vos!" Entretanto, o movimento sindical se organizou preponderantemente dentro de bases nacionais.

3 Confederações Internacionais de Sindicatos, ou Global Union Federations. 
InterAção | 165

encontra seu arcabouço teórico, neste período, nos argumentos Neo-liberais. A própria cooperação entre classes traz em seu bojo um termo fundamental - cooperação-, bem como dois atores fundamentais da relação capital-trabalho: as empresas (multinacionais) e os sindicatos (internacionais), variáveis de análise impensáveis nos marcos do Realismo Clássico.

A escolha pelo debate na década de 70 foi devida a um fator-chave: o aumento da frequência de internacionalizações de empresas, fato que ocorreu a partir da década de 60, sendo mais intensa a partir dos anos em questão (COX, 1971, p. 559 e 563). A internacionalização de uma empresa leva à descentralização de sua cadeia produtiva e, assim como acontece no sistema Ohno de produção, a capacidade de organização dos trabalhadores e de respostas às estratégias empresariais tornam-se mais difícieis ou morosas. É este o quadro que muitos sindicalistas passam a enfrentar a partir dos anos 70 .

Nota-se que nosso contexto histórico data de quatro séculos de distância. Nosso objetivo, neste artigo, não é explicar todas as mudanças estruturais que ocorreram no mundo desde esta década até os dias atuais, mas pincelar alguns debates que possibilitaram a discussão em torno da prática de transnacionalização de processos e atores, além de destacar outros debates em torno do tema. Para tanto, começaremos contextualizando quais fatos históricos tornaram o ambiente acadêmico propício para o debate sobre o transnacionalismo.

Ao final do artigo procuraremos demonstrar a efetiva internacionalização das demandas de trabalhadores, via estudo de caso (BASF), ocorrida justamente no período em questão (década de 70). O método utilizado será o indutivo. Partiremos da realidade 
166 | InterAção

concreta para formular conclusões que acreditamos parcialmente livres de preceitos prescritos.

Década de 1970: fatores-chave que contribuíram para a virada paradigmática do Realismo Clássico para o Debate Racionalista (Neo-realismo versus Neo-liberalismo).

No começo da década de 70, alguns acontecimentos decisivos mostraram ao debate acadêmico nas Relações Internacionais que o paradigma Realista, como corrente, já não supria todas as necessidades teóricas de explicação para nova configuração do Sistema Internacional.

Talvez o acontecimento mais significativo tenha sido o descongelamento das relações Leste-Oeste, ainda sob a égide da Guerra Fria (GF). Na deténte as grandes potências ainda estavam negociando, principalmente, a questão da segurança. A segurança, entretanto, já não é entendida apenas como mera sobrevivência dos Estados.

Um exemplo claro da defasagem do militar como item provido apenas pelo Estado, entra em questionamento ao final da Guerra do Vietnã: os vietnamitas, de chinelos e aparato militar débil (isto é, sem os quilos de equipamentos ou a tecnologia militar provida pelo Estado) saíram vitoriosos da Guerra, ainda que haja controvérsias sobre esta asserção.

A análise realista clássica de Morgenthau, que aborda o Estado como ator central nas relações internacionais, é débil para analisar a Guerra do Vietnã. O poderio militar estatal, se tomado como única variável de análise, torna-se igualmente um argumento frágil. Assim, no ano de 1971, em pleno conflito, o realismo se arrefece. 
InterAção | 167

Outro ponto está relacionado à Crise do Petróleo, suscitada pela OPEP:

(...) a inflação global da década de 1970 e do início dos anos 1980, causada por um aumento súbito e dramático nos preços do petróleo pelo cartel da Opep (...), relembrou quanto as interconexões da economia global podem ameaçar o bem-estar nacional e pessoal em qualquer lugar do mundo. No caso do choque do petróleo de 1970, ficou nítido para inúmeros motoristas norte-americanos, europeus e japoneses - entre outros - que as políticas econômicas do Oriente Médio e de outros importantes produtores de petróleo têm o poder de aumentar o preço da gasolina ou petróleo, reduzindo seus padrões de vida. (JACKSON e SORENSEN, 2007, p. 27).

Em outras palavras, o argumento de um SI com um único e forte país, como o defendera Aron, se mostrou, ao menos parcialmente, falacioso. Neste momento foram organizações ou países "mais fracos" que ditaram regras comerciais aos países dependentes de petróleo.

Some-se à Crise o fim do Bretton Woods e teremos, no campo econômico, questionamento no que concerne quem é o verdadeiro promotor do bem-estar social: os EUA e a Europa já não são Estados tão fortes.

O fim de Bretton Woods apresentou um variado espectro de fatos: em primeiro lugar, o fim do alinhamento da França aos Estados Unidos, expressado pelas declarações de Charles de Gaule, representava também o fim da hegemonia norte-americana. Segundo, a Guerra do Vietnã e a crise da libra inglesa (1967) fizeram com que os países se voltassem aos seus problemas internos. Em terceiro lugar, o próprio regime de convertibilidade sofre crise. 
Essas questões expressam a fraqueza do Estado - em especial os EUA - como ente forte no SI. A robustez da economia estadunidense dá passagem à ascensão de novos países: surgem os Novos Industrializados (New Industrialized Countries - NICs) como o Brasil e o México, e os Tigres Asiáticos (Hong Kong, Cingapura, Coréia do Sul e Taiwan). Novamente aqui os debates estão relacionados a países que antes não eram destaque nas relações de poder, como Cuba e Leste Europeu.

Também surgem novos debates, "alternativos" ao mainstream realista. A CEPAL (Comissão Econômica para América Latina e Caribe) foi uma iniciativa latino-americana de pensar o desenvolvimento latino-americano. Há, aqui, quebra com a visão estadunidense ou européia de como deveria funcionar o SI.

Aponta Theotônio dos Santos, utilizando-se inclusive de jarguões neoliberais:

\footnotetext{
Uma relação de interdependência (...) torna-se uma relação dependente quando alguns países são capazes de se expandir através do auto-impulso, enquanto outros (...) só podem expandir-se como reflexo da expansão dos países dominantes. (SANTOS apud. MERQUIOR, 1996, pp. 187-189).
}

Hein ainda argumenta que "o modelo realista e o desenvolvimentismo nacionalista serão permanentemente referidos nos debates sobre as relações Norte-Sul”. (2000, p.5)

Por fim, o TNP induziu a necessidade de novas categorias de análise: leste-oeste, norte-sul, congelamento do poder mundial. $\mathrm{O}$ Tratado também passa a ser contestado pelos países que não podiam 
InterAção | 169

adquirir arsenais nucleares, em claro questionamento ao equilíbrio de poder mundial. Em 1968 o então embaixador brasileiro João Augusto de Araújo Castro contesta o privilégio de apenas alguns países, notadamente potências nucleares, em manter tal aparato:

Em fevereiro de 1968, durante a sessão da Comissão de Desarmamento realizada em Genebra para tratar do projeto de Tratado de Não-Proliferação de Armas Nucleares, o chefe da delegação brasileira, embaixador João Augusto de Araújo Castro, criticou duramente o instrumento por "perpetuar situação em que as potências nucleares poderiam manter seus arsenais e os demais deveriam assumir compromissos e controles externos". (BARRETO FILHO, 2006, p. 100).

De acordo com Oswaldo Reis, sequer o neo-realismo é capaz de entender a problemática no Cone Sul. $\mathrm{O}$ autor argumenta que "a abordagem teórica a ser utilizada [para entender a América Latina] é o realismo neoclássico, que busca articular a variável doméstica para refinar a variável sistêmica, para explicar a gênese do terror nuclear". (REIS, 2009, p.7).

Portanto, na década de 1970, a idéia é que mesmo sob a GF haja espaço para uma literatura que trata de cooperação, fomentada não apenas pelo Estado. Como apontam Baylis, Smith e Owens sobre a fragilidade do Realismo Clássico:

The peaceful conclusion of the cold war caught many realists off guard. Given that many realists claim a scientific basis to their casual account of the world, it is not surprising that their inability to foresee the dynamics that led to the end of the bipolar cold war system sparked the publication of several poweful critiques of realist theory. Critics 
170 | InterAção

also maintained that realism was unable to provide a persuasive account of new developments such as regional integration, humanitarian intervetion, the emergence of a security community in Western Europe, and the growing incidende of intra-state war wracking the global South. In addtition, proponents of globalization argued that Realism's privileged actor, the state, was in decline relative to non-state actors such as transnational corporations and powerful regional institutions (...). (BAYLIS, SMITH e OWENS, 2008, p. 94)

Os autores ainda destacam do Neo-liberalismo, atores e níveis de análise intrínsecos ao objeto deste artigo, a transnacionalização sindical:

[The] argument about the positive benefits from transnational cooperations is one which informed a new generation of scholars (particularly in the USA) in the 1960s and 1970s. Their argument was not simply about the mutual gains from trade, but that other transnational actors were begining to challenge the dominance of sovereign states. (...). In one of the central texts of this genre, Robert Keohane and Joseph Nye (1972) argued that the centrality os other actors, such as interested groups, transnational corporations, and international non-governmental organizations (INGOs) had to be taken into consideration (...). (BAYLIS, SMITH e OWENS, 2008, p. 114115).

Podemos concluir preliminarmente que o sindicalismo transnacional, se antes órfão de literatura que abrangesse todas as suas necessidades explicativas, seja pela rigidez estadocêntrica da visão realista clássica, seja pela visão idealista do liberalismo, encontra parcialmente na literatura neo-liberal, algum espaço para desenvolver argumentos que se aproximem de sua própria realidade. 
Outras escolas das Relações Internacionais, como Gramsciana, Teoria Crítica, Sistema-mundo, Construtivismo, Copenhague, Inglesa, Sociologia Histórica, Feminismo, Pós-modernimo e Pós-colonialismo, dentre outras, certamente contribuiram para o enriquecimento do debate acadêmico, sendo mais ou menos adequadas ao estudo de novas formas de sindicalismo.

Não é escopo deste artigo, contudo, pincelar todas as Teorias de Relações Internacionais existentes na Academia, mas fazer um paralelo entre coincidências históricas, isto é, os eventos ocorridos na década de 70 - inclusive os sindicais -, o arrefecimento do Realismo Clássico e a ascensão do Neo-liberalismo como paradigmas teóricos.

Feitas essas considerações e destacando os marcos do Neo-liberalismo pretendemos, no próximo item, demonstrar exames análogos ao transnacionalismo sindical na década em questão.

\section{Contribuições teóricas de autores sobre a transnacionalização sindical nos marcos do Neo-liberalismo inaugurado na década de 70.}

Conforme dissemos anteriormente, a transnacionalização de práticas como economia, relações de trabalho, Organizações Não-Governamentais, multinacionais, a Igreja, finanças e ciência, refletiram na Academia "novos debates", trazendo ao liberalismo renovado destaque.

Nosso marco teórico é quando da multiplicação de empresas multinacionais e, conseqüentemente, dos investimentos diretos externos (IED) e do nascimento de práticas transnacionais de sindicalismo. De acordo com o relatório do Ministério do Desenvolvimento, 
172 | InterAção

Indústria e Comércio Exterior - MDIC:

A integração produtiva e comercial no mundo vem ocorrendo de maneira significativa. Enquanto o PIB mundial cresceu 15 vezes em termos nominais, de 1970 a 2007 , as exportações mundiais aumentaram 42 vezes, evidenciando como as cadeias de mercadorias vêm se internacionalizando. Os fluxos de IDE, por sua vez, embora tenham apresentado considerável volatilidade ao longo do tempo e demonstrado forte queda e recuperação após o ano 2000, elevaram-se 150 vezes no mesmo período (...). (MDIC, 2009, p.10).

No começo desta mesma década, em 1971, Robert Keohane e Joseph Nye publicaram um livro, "Transnational Relations and World Politics”, no qual, com muita parcimônia, começavam a chamar atenção para as novas características do Sistema Internacional.

No que concerne ao movimento sindical, se antes as cadeias produtivas se localizavam em territórios nacionais e, portanto, tinham as bases sindicais localizadas nestes, no começo dos 70 esta organização também passou a repensar e, mais importante, reformular sua ação frente às novas táticas e estratégias das empresas multinacionais.

Cox, em seu artigo "Labor and Transnational Relations" 4 apontou justamente nesta direção. $\mathrm{O}$ autor destacou que, na maior parte do século XIX, as relações de trabalho eram pensadas dentro dos limites territoriais do Estado. Este, por sua vez, era visto como um instrumento para atingir as metas dos trabalhadores. A Grande Depressão de 1929

4 Cox, ainda que tenha sido um dos precurssores da Teoria Crítica, escreve este artigo no mencionado livro de Keohane e Nye, inaugurando o Neo-liberalismo. Por este motivo 0 consideramos como um autor que escreveu sob o marco desta escola. 
parecia ser o fato comprobatório dessa assertiva: Keynes corroborava, com sua teoria, o papel desenvolvimentista do Estado. A OIT, segundo o autor, não seria uma organização para fomentar a solidariedade de classe, mas um instrumento de alguns países sobre outros para praticar o enforcement de suas práticas laborais internas. O principal objeto de análise para as relações trabalhistas, segundo a perspectiva de Cox, portanto, ainda se baseava no papel do Estado.

Note-se que este tipo de análise se aproxima, em grande medida, do viés estadocêntrico da teoria Realista das Relações Internacionais.

A mudança no modo de agir dos sindicatos foi apontada pelo autor a partir de manobras da Federação Internacional dos Trabalhadores Químicos (International Chemical Federation - ICF, em inglês), uma Global Union Federation (GUF) que, em 1969 coordenou uma confrontação à empresa Saint Gobain ${ }^{5}$ da Alemanha, França, Itália e Estados Unidos. Para o autor, essa era uma nova política do sindicato, que não envolvia diretamente qualquer governo ou política nacional.

A estratégia desta Global Union baseou-se na internacionalização do PLR (Participação nos Lucros e Resultados) para os cálculos de recebimento dos trabalhadores estadunidenses: os trabalhadores da Saint Gobain nos EUA foram notificados que não receberiam seus PLRs, pois a subsidiária da empresa não havia lucrado com as suas operações em território nacional ${ }^{6}$, apesar possuir tais lucros no

5 Empresa francesa de fabricação de vidros, abrasivos, cerâmicas e plásticos, dentre outros.

6 A falta de lucro ou até mesmo o saldo negativo nos resultados de uma empresa são eventos corriqueiros: muitas vezes uma única empresa possui diversos C.N.P.J.s (Cadastro Nacional de Pessoa Jurídica) e um pode lucrar em detrimento do outro, ain- 
174 | InterAção

Balanço Consolidado. $\mathrm{O}$ sindicato estadunidense obteve tais informações com os sindicalistas de outros países. A saída encontrada foi reivindicar Participação nos Lucros e Resultados tendo como base os resultados Companhia em âmbito global, ou seja, envolvendo todos os países no qual a empresa operava e refazendo o cálculo de PLR sobre outra base, desta vez superavitária.

Note-se que esta análise, diferentemente da anterior, destaca qualidades como cooperação e comunicação (entre dois atores novos, os sinsicalistas), distanciando-se do estudo Realista das Relações Internacionais e aproximando-se do paradigma Neo-liberal.

A literatura que trata da transnacionalização de práticas sindicais é ampla e envolve diversos temas de natureza Neo-liberal, como cláusula social, governança global, relação entre política doméstica e internacional, redes sociais e sociedade civil internacional.

Abordaremos, neste artigo, três discussões fundamentais da corrente Neo-liberal que problematizam sua análise, quais sejam: (i) universalidade/ relatividade; (ii) spillover/ exclusão e (iii) soberania/ intervencionismo.

\section{Primeira discussão problematizadora do paradigma Neo-liberal relacio- nada à transnacionalização sindical: universalidade vs. relatividade}

O embate entre universalidade e relatividade não é novo; basta lembrar a crítica contundente ao idealismo normativo kantiano,

da que o Balanço Consolidado seja positivo. Uma empresa Saint Gobain com C.N.P.J prestadora de serviços fabris certamente não trará o mesmo lucro do C.N.P.J. prestador de serviços financeios. 
InterAção | 175

onde a moral e a ética universais, substituem problematizações e particularidades dentro dos Estados-nação.

No caso da transnacionalização sindical, o que seu proponentes sugerem não é a universalização de standards trabalhistas, para todos os ramos, categorias, países e cultura. Trata-se, neste caso, de um conjunto de sindicatos unidos que, a partir de objetivos comuns, procuram atingir metas, que beneficiarão algumas centenas ou milhares de pessoas, mas não a população mundial. A especificação de interesses em um grupo específico que partilha dos mesmos princípios e práticas parece, portanto, findar tal discussão. Como argumenta Gerda van Roozendaal:

Although it may be tempting to conclude from sources that there is na international consensus that these labour rights are applicable under all circumstances, this is far from true. Three objections to such a conclusion can be raised: (a) the notion of universality does not mean uniformity; (b) universality is not always recognized in practice or in principle; and (c) even if they are universal, there exists no agreement on the best way to enforce these labour standards. (2002, p. 44).

\section{Segunda discussão problematizadora do paradigma Neo-liberal relacio- nada à transnacionalização sindical: soberania vs. intervencionismo}

O debate soberania/ intervencionismo diz, por um lado, que o princípio de não-intervenção no Estado é consagrado e costume nas relações internacionais e, assim sendo, deve ser respeitado. Assim, é prerrogativa do Estado não incorporar em sua legislação algumas regras de respeito ao trabalhador. Por outro lado, as vozes a favor do in- 
176 | InterAção

tervencionismo são grupos, como os próprios sindicatos, que não vêem suas demandas atendidas pelo Estado (por exemplo, os Estados Unidos e o Brasil nunca ratificaram a Convenção 87 da OIT, sobre liberdade sindical). Neste embate, a relação se dá entre Davi e Golias: de um lado, muitos grupos de interesse não assistem as suas reinvindicações atendidas pelo próprio Estado onde habitam. De outro, o Estado quer manter sua plena soberania e legislar sem interferências no âmbito interno.

Este debate tem como fundo um ator fundamental e extremamente forte: o Estado. Este, a priori, deve atender todos interesses dos grupos reinvindicadores, isto é, os interesses tanto de empresários, quanto de sindicalistas. As demandas destes dois atores, contudo, se concentram em pontos extremos da balança e parecem não ter pontos em comum. Caimos, aqui, na discussão do próprio conceito de democracia.

Em termos práticos, as empresas de países onde o diálogo social é mais avançado procuram ter cartilhas de Responsabilidade Social Corporativa (RSC) que são aplicadas dentro das empresas, sem a necessidade de aprovação dos Congressos nacionais onde as empresas têm plantas produtivas.

\section{Terceira discussão problematizadora do paradigma Neo-liberal relacio- nada à transnacionalização sindical: spillover vs. exclusão}

Quanto ao spillover ${ }^{7}$ vs. exclusão, utilizaremos com relação ao primeiro o conceito de Zacher, ainda que demasiado otimista: a idéia

7 Spillover, ou transbordamento, pode ser entendido como o "contágio" de práticas, usos e costumes de uma comunidade política para outra. 
de transbordamento da cooperação, gerando efeitos automáticos, multiplicadores e sistemáticos.

Os estudiosos da transnacionalização sindical já se depararam algumas vezes com casos nos quais os sindicatos locais, notadamente nos países em desenvolvimento, eram contra a inclusão de algumas cláusulas sociais em seu mercado de trabalho. $\mathrm{O}$ argumento utilizado pelos sindicalistas dos países em desenvolvimento é que sua população precisa antes de empregos, para depois reinvindicar direitos, ou seja, o Estado de bem-estar social não poderia existir antes da existência de inúmeros e variados empregos. O spillover e a cláusula social, neste caso, estariam mais próximos do enforcement que do transbordamento.

Dentre os argumentos a favor do spillover, destaca-se o raciocínio de que as diferenças trabalhistas, principalmente aquelas relacionadas aos salários, criam uma "vantagem comparativa" que traria ao comércio internacional desigualdade de condições: basta observar o dumping social.

Este tipo de argumento é, em especial, aquele dos trabalhadores de países desenvolvidos que, portadores de altos salários, temem perdê-los para trabalhadores de outros países onde não existam encargos trabalhistas ou diálogo social de alto nível, como na China. Outro argumento defende que devem existir regras gerais de regulação do trabalho, assim como o é a regulamentação do comércio. A fraqueza deste segundo argumento está na própria vontade dos trabalhadores: se a assertiva de que todos os países desejam participar do comércio internacional é correta, a mesma não o é para os trabalhadores: há sindicatos, como já abordamos, que não desejam participar da cláusula social que regulamentaria o trabalho, mas desejam os empregos 
178 | InterAção

provenientes do desenvolvimento econômico/ comercial.

O debate spillover vs. exclusão parece não chegar a consenso. O que se observa, na prática, é a inclusão de cláusulas sociais em contratos comerciais entre países específicos, como é o caso dos Estados Unidos e a maioria dos países da Europa Ocidental.

\section{Estudo de caso: a BASF (Badische Anilin und Soda-Fabrik)}

O caso da internacionalização sindical dos trabalhadores da empresa BASF e sua atuação na região do Grande $\mathrm{ABC}$ têm início justamente em nosso marco histórico e se desenvolve até os dias atuais.

Nos idos da década de 1970 começou a desenvolver-se na região um grande pólo petroquímico. Como já existiam empresas do ramo automobilístico, principalmente em São Bernardo e Santo André, deve-se a estas empresas o aparecimento de outras, como as do ramo químico e plástico, como a BASF, para atender as demandas de grandes montadoras. Nota-se, também, o desenvolvimento de pequenas empresas de prestação de serviço e de autopeças, respectivamente para o atendimento de terceirização dessas empresas e fornecimento das pessas intermediárias do processo produtivo.

Os estudos acadêmicos que abordaram os movimentos sindicais de 1978 e 1979, em plena ditadura militar, são abundantes e não é nosso objetivo repeti-los aqui. Apontamos, apenas, que tais movimentos foram importantes também para o desenvolvimento de redes sindicais na BASF. De acordo com Drummond, foi no ano de: 
InterAção | 179

talúrgicos de São Bernardo, Químicos de Santo André, enviaram pedidos de solidariedade aos seus colegas sindicalistas europeus e recebessem a visita solidária de ativistas políticos de esquerda, padres e pastores de igrejas, principalmente da Alemanha e Bélgica. (2008, p. 15-16)

Segundo informações da "Rede de Trabalhadores (as) na BASFl", "na América do Sul, a multinacional alemã ignorava as normas e diretrizes internacionais da Organização Internacional do Trabalho (OIT)" (p. 8). Note que aqui temos convergência de opiniões entre a cultura sindical local e os standards de trabalho da OIT, isto é, os sindicatos brasileiros não só desejavam o spillover de práticas trabalhistas européias, como pediam ajuda de seus companheiros com mais experiência para tanto.

No começo da década de 1980, estes mesmos padres e pastores eram agentes de intercâmbio entre a experiência européia o incipiente movimento brasileiro. A formação da comissão de fábrica da BASF:

(...) se originou após a conquista da Comissão de Fábrica na unidade BASF Glasurit e Isopor em São Bernardo, durante a década de 1990.

Os contatos internacionais do sindicato dos químicos de Santo André, visando buscar apoio para a Comissão de Fábrica da BASF, em suas lutas, coincidiram com um lockout, decretado pela direção da BASF, em sua unidade localizada em Geismar, Louisiana, EUA, no ano de 1989, rompendo negociações com o sindicato local.

Esse fato, acontecido nos Estados Unidos com uma multinacional alemã, levou os norte-americanos a buscarem solidariedade em diversos locais, incluindo o Brasil, que recebeu a visita de um dos 
180 | InterAção

dirigentes locais, Richard Leonard. O sindicato dos químicos de Santo André, junto com a Comissão de Fábrica da BASF, realizou uma assembléia com os trabalhadores, na unidade Glasurit em São Bernardo, em solidariedade aos companheiros norte-americanos, vitimas da intransigência da empresa em continuar as negociações em Geismar.

As lutas em Geismar e São Bernardo levaram o sindicato alemão a se posicionar mais fortemente em apoio e solidariedade internacional ao Brasil e aos EUA e, em seguida, a realizar diversos encontros na Alemanha e no Brasil. (DRUMMOND, 2008, p. 18-19).

Outro acontecimento que reflete a transnacionalização das relações de trabalho, permitida apenas após o pontapé incial na empresa, na década de 1970, foi a formação de uma rede regional de sindicatos, desta vez sul-americana:

(...) a ICEM [International Federation of Chemical, Energy, Mine and General Workers' Unions], promove o I Encontro Internacional dos Trabalhadores da BASF [em 1999]. A iniciativa de impulsionar a organização de trabalhadores de uma mesma empresa multinacional para a criação de Redes partiu de uma decisão do Congresso da entidade.

O Encontro resultou na criação da Rede de Trabalhadores sul-americana, com o objetivo de garantir um intercâmbio permanente entre os trabalhadores das plantas da BASF em todo o continente e abrir um novo canal de negociação com a direção da empresa, já então a maior corporação química do mundo. Em 1999, a BASF possuía 20 plantas na América do Sul. (REDE DE TRABALHADORES NA BASF AMÉRICA DO SUL, 2009, p. 13)

Foi, contudo, apenas em 2002 que a direção da BASF reconheceu a Rede Sul Americana de Sindicatos da BASF. Atualmente, 
InterAção | 181

os sindicatos dos trabalhadores da BASF estão no âmbito da ICEM e procuram assinar um Acordo Marco Global (International Framework Agreement, em inglês) com a empresa.

\section{CONSIDERAÇÕES FINAIS}

O debate sobre o transnacionalismo passa a ter espaço a partir da década de 1970, dentro do arcabouço teórico oferecido pelo neo-liberalismo em contraponto ao realismo clássico; outros debates, não focados apenas no poder e na racionalidade dos Estados passam a ganhar projeção e o velho debate realista clássico já não abarca todas as grandes questões das RI, como vimos em Morgenthau e Aron. Esse novo liberalismo, entretanto, não é mais o idealismo normativo kantiano, mas um debate que, com novo fôlego, se aproxima melhor da realidade.

Portanto, há uma mudança fundamental no pensamento acadêmico das Relações Internacionais: com a projeção da literatura neoliberal e do neorealismo (o debate racionalista), passam a entrar em cena abordagens mais ricas e complexas. Longe de entrarem em consenso, o embate "neo x neo" trouxe maior riqueza intelectual para a Academia.

De fato, o objeto de estudo abordado neste trabalho, o transnacionalismo, jamais caberia em um debate puramente "realista", uma vez que a relação direta entre trabalhadores e empresas traz ao campo de estudo novos atores e níveis de análise. Como aponta Cox, essa forma de fazer sindicalismo estava, na década de 70, caminhando para a descentralização e a visão não estatal, possível pelo fato de que, 
com a deténte, os sindicatos puderam deixar de se preocupar primordialmente com a Guerra Fria e o futuro do capitalismo.

Inúmeros autores foram influenciados pelos fundadores da escola neoliberal (Robert Keohane e Joseph Nye), como Stephen Krasner, Robert Axelrod, James Rosenau, Oran Young e Andrew Moravcsik, e outros tantos pela escola neorrealista (que, como vimos, tem Kenneth Waltz como fundador): Barry Buzan, Richard Little, John Mearsheimer e Stepehn Walt, para citar os principais. Naturalmente esses debates refletem o mainstream das RI e não abarcam correntes como o pós-colonialismo, pós-modernismo e a teoria verde, dentre outros.

De qualquer forma, o debate "neo x neo" inaugurou novas categorias de análise nas RI, como o realismo ofensivo de Mearsheimer, os regimes de Krasner, a governança de Young e Rosenau e a valorização das instituições pelos neoliberais, dentre outros, bem como inaugurou uma nova agenda de pesquisa para temas como os movimentos sociais, como vimos ser o caso sindical apresentado neste artigo.

Se na década de 70 a abordagem de temas transnacionais requeria precauções especiais, no final da primeira década do século XXI, tal debate nos pareceu essencial para fundamentar temas à época inéditos e entender historicamente debates posteriores aos mencionados, como o construtivismo e a teoria crítica.

\section{REFERÊNCIAS}

BARRETO FILHO, Fernando P. de Mello. Os Sucessores do Barão: Relações Exteriores do Brasil. 1964 a 1985. São Paulo: Paz e Terra, 2006 
InterAção | 183

BAYLIS, John; SMITH, Steve e OWENS, Patricia. Globalization Of World Politics. Oxford, 2008.

COX, Robert W. Labor and Transnational Relations. In. KEOHANE, Robert O. e NYE, Joseph. Transnational Relations and World Politics. Massachusetts: World Peace Foundation, 1971.

DRUMMOND, José. Redes sindicais em empresas multinacionais como resposta sindical à globalização econômica. Artigo produzido para a Conferência Anual Internacional da Universidade Global do Trabalho. Campinas, 2008.

HEIN, L. Lothar C. Guerra Fria: conceitos e problemas. Paper, 2000.

JACKSON, Robert e SORENSEN, Georg. Introdução às Relações Internacionais. Rio de Janeiro: Zahar, 2007.

KEOHANE, Robert O. e NYE, Joseph. Transnational Relations and World Politics: An Introduction. In: KEOHANE, Robert O. e NYE, Joseph. Transnational Relations and World Politics. Massachusetts: World Peace Foundation, 1971.

Ministério do Desenvolvimento, Indústria e Comércio Exterior (MDIC). Termo de referência: internacionalização de empresas brasileiras. Brasília, 2009.

REDE DE TRABALHADORES NA BASF AMÉRICA DO SUL: 10 anos de Solidariedade Sindical e Diálogo Social. Revista Rede BASF. Sindicato dos Químicos do ABC: Santo André, 2009.

ROOZENDAAL, Gerda von. Trade Unions \& Global Governance: The Debate on a Social Clause. 1a. ed., Londres: Continuum, 2002. 
184 | InterAção

SANTOS, Theotonio dos. "The structure of Dependence" Apud. Merquior, José Guilherme. "Dependência." In: BOTTOMORE, T. Dicionário do Pensamento Social do Século XX. Rio de Janeiro, Editora Jorge Zahar, 1996, pp. 187-189.

WALTZ, Kenneth N. Theory of international politics. New York: Newbery Award Records, 1979.

ZACHER, Mark. Os pilares em ruína do templo de Vestfália: implicações para a governança e a ordem internacional. In: James Rosenau e Ernst Otto Czempiel (orgs). Governança sem governo: ordem e transformação na política mundial. Brasília: Ed. UnB, 2000, p.83-141. 